ISSN 0103-9954

\title{
MASSA ESPECÍFICA BÁSICA E MASSA SECA DE MADEIRA DE Eucalyptus grandis SOB O EFEITO DO ESPAÇAMENTO DE PLANTIO E DA POSIÇÃO AXIAL NO TRONCO
}

\section{BASIC DENSITY AND DRY MASS OF WOOD OF Eucalyptus grandis AS AFFECTED BY TREE SPACING AND TRUNK POSITION}

\author{
Márcio Goulart $^{1}$ Clovis Roberto Haselein ${ }^{2} \quad$ Juarez Martins Hoppe ${ }^{3}$ \\ Jorge Antônio Farias ${ }^{4}$ Dalva T. Pauleski ${ }^{5}$
}

\begin{abstract}
RESUMO
Neste trabalho, foram investigadas a massa específica básica e a massa seca de madeira e de casca de Eucalyptus grandis W Hill ex-Maiden em função de 12 espaçamentos de plantio. A madeira foi retirada de árvores procedentes de unidades experimentais da AFUBRA com idade aproximada de 10 anos. Foram utilizadas 36 árvores (três por parcela) nos ensaios. Discos na base, DAP, 25, 50, 75 e 100\% da altura comercial foram retirados de cada árvore para determinação da massa específica básica da madeira e da casca. Exceto para os menores espaçamentos, houve uma redução da massa específica básica e da massa seca de madeira e de casca com o aumento do espaço vital. Os espaçamentos entre linhas de plantio que produziram os maiores valores das variáveis estudadas situaram-se entre 1,5 e $2 \mathrm{~m}$.
\end{abstract}

Palavras-chave: massa específica básica, Eucalyptus grandis, espaçamento.

\begin{abstract}
The basic density and dry mass of wood and bark of Eucalyptus grandis W Hill ex-Maiden of growing under twelve tree spacing were investigated. Thirty six trees (three per unit), with age of approximately ten years, coming from experimental units of AFUBRA, were used. Disks at base, DBH, 25, 50,75 and $100 \%$ of trunk commercial height were taken from each tree for determination of wood and bark basic densities. Except for the smaller tree spacing, there was a decrease in basic density and dry mass of wood and bark with increasing planting spacing. The between lines tree spacing that produced the larger values of the studied variables were from 1,5 to $2 \mathrm{~m}$.
\end{abstract}

Key words: basic density, Eucalyptus grandis, tree spacing.

\section{INTRODUÇÃO}

O uso de florestas para fins energéticos continua expressivo no Brasil. Apesar dos avanços tecnológicos, poucos combustíveis podem competir com a madeira em termos de custos, tanto para uso industrial quanto para residencial. Por ser renovável, ao contrário dos combustíveis fósseis e, em especial, a madeira proveniente de florestas plantadas, possui boa aceitação pelo mercado consumidor.

As florestas de eucalipto têm sido as preferidas para essa finalidade, por apresentarem excelente produção volumétrica e boas características da madeira. Muito tem sido alcançado com o melhoramento genético e o manejo dos povoamentos. As práticas silviculturais são uma forma de melhorar ainda mais a performance das florestas e adequá-las aos objetivos dos produtos finais. Dentre essas práticas cabe destacar a fertilização, o desbaste, a desrama e, sobretudo, o espaçamento inicial de plantio: além do volume produzido, o espaçamento pode afetar as características da madeira. Para Berger (2000), em florestas de ciclo curto, o espaçamento pode afetar direta e rapidamente a qualidade da madeira produzida.

1. Engenheiro Florestal, Centro de Ciências Rurais, Universidade Federal de Santa Maria, CEP 97105-900, Santa Maria (RS).

2. Engenheiro Florestal, PhD., Professor do Departamento de Ciências Florestais, Centro de Ciências Rurais, Universidade Federal de Santa Maria, CEP 97105-900, Santa Maria (RS). haseleic@ccr.ufsm.br

3. Engenheiro Florestal, Dr., Professor do Departamento de Ciências Florestais, Centro de Ciências Rurais, Universidade Federal de Santa Maria, CEP 97105-900, Santa Maria (RS). hoppe@ccr.ufsm.br

4. Engenheiro Florestal, Técnico da Assocaição dos Fumicultores do Brasil (AFUBRA), Rua Julio de Castilhos, 1021, CEP 96800-000, Santa Cruz do Sul (RS). farias@afubra.com.br

5. Engenheira Florestal, Acadêmica do Programa de Pós-graduação em Engenharia Florestal, Centro de Ciências Rurais, Universidade Federal de Santa Maria, CEP 97105-900, Santa Maria (RS).

Recebido para publicação em 25/06/2003 e aceito em 22/09/2003. 
Nas determinações da qualidade da madeira, a massa específica básica (ME) é o índice mais utilizado, pois se correlaciona diretamente com o rendimento em massa e também com as propriedades físico-mecânicas da madeira (Brasil e Ferreira, 1971). Segundo Ribeiro e Zani (1993) a ME pode limitar a escolha do material genético de acordo com a finalidade. Por exemplo, a produção de carvão vegetal para siderurgia ou dormentes para estrada de ferro requer madeira de alta massa específica. Por outro lado, as fábricas de celulose de fibra curta, chapas aglomeradas e chapas de fibra normalmente trabalham com espécies de massa específica intermediária. Já a quantidade de energia produzida está intimamente relacionada à massa seca (MS) de madeira (Stamm, 1964). Quanto maior a massa da madeira, maior será a quantidade de energia fornecida.

O presente trabalho teve como objetivo estudar as variações na ME e na MS da madeira e da casca de florestas de Eucalyptus grandis W Hill ex-Maiden em função do espaçamento de plantio e da posição axial no tronco.

\section{REVISÃO DE LITERATURA}

\section{O espaçamento}

Para Smith (1962), o número ideal de árvores por unidade de área deve ser determinado pela quantidade que pode crescer tirando o melhor e maior proveito dos fatores de crescimento, produzindo o maior volume de produtos florestais de dimensões, forma e qualidade mais convenientes.

Balloni e Simões (1980) relatam que a escolha do espaçamento de plantio na maioria dos planejamentos florestais tem se fundamentado simplesmente no uso final da madeira, ignorando-se outros fatores ecológicos e/ou silviculturais de suma importância.

\section{Variações da massa específica básica}

Conforme Bampi (1991), para o manejo florestal, interessa saber até que ponto se pode controlar a qualidade da madeira. Para isso, é necessário um certo conhecimento das propriedades que determinam a qualidade da madeira e até que ponto estas são influenciadas pelas características genéticas e pelas modificações do ambiente (espaçamento, proporção de copa viva e a taxa de crescimento).

Para Busnardo et al. (1987), a massa específica da madeira é uma característica bastante complexa, resultante da combinação de caracteres anatômicos, físicos e químicos. A respeito da variabilidade da massa específica básica, deve-se considerar as variações existentes entre gêneros, entre espécies pertencentes ao mesmo gênero bem como entre árvores de um povoamento.

A massa específica básica é influenciada por diversos fatores, tais como: espessura da parede celular, quantidade de vasos, dimensões da fibra, teor de extrativos, origem de semente, condições edafoclimáticas, sistema de implantação e condução da floresta. Ela varia significativamente em função da taxa de crescimento, local de origem, espaçamento, idade, procedência, entre gêneros, espécies, entre árvores da mesma espécie, e dentro da mesma árvore e ainda no sentido base-topo e medula-casca (Foelkel et al., 1975; Ferreira e Kageyana, 1978; Tomazello Filho, 1985; Souza et al. 1986; Busnardo et al., 1987).

Ferreira (1970) concluiu que, para o Eucalyptus saligna com idades de 5 e 7 anos, houve um acréscimo da massa específica média da árvore em função do DAP, isto é, as árvores mais vigorosas apresentaram, em média, maior massa específica básica que as menos vigorosas. Entretanto, ocorriam variações individuais, podendo ser encontradas árvores mais vigorosas com baixa massa específica básica média e árvores não-vigorosas com massa específica alta. Muitos autores acreditam que quanto maior o crescimento em diâmetro, menor é a massa específica básica o que, na realidade, não é regra geral para o Eucalyptus (Souza et al., 1986). O mesmo fato foi observado por Ferreira e Kageyama (1978) que concluíram que as árvores mais vigorosas de populações híbridas de Eucalyptus grandis e Eucalyptus saligna apresentavam maior massa específica, sendo que, para Eucalyptus grandis, não encontraram efeito da taxa de crescimento sobre a massa específica.

Carvalho e Camargo (1996) estudaram a variação da massa específica básica entre três procedências e 53 progênies de Eucalyptus saligna com 6 anos de idade. Esses autores não verificaram nenhuma diferença significativa ao nível de $5 \%$ na comparação das três procedências. No entanto, comparando as

Ciência Florestal, v. 13, n. 2, 2003 
progênies uma a uma, foram verificas diferenças significativas nas massa específicas básicas as quais variaram entre 0,446 a $0,538 \mathrm{~g} / \mathrm{cm}^{3}$.

\section{Dentro da árvore no sentido base-topo}

A literatura apresenta dados contrastantes em relação à variação da massa específica básica da madeira no sentido base-topo. Para o gênero Eucalyptus, observa-se, com maior freqüência, ME decrescente até $50 \%$ da altura da árvore e crescente desse ponto até o topo ou ainda podendo diminuir próximo ao topo. Busnardo et al. (1987), estudando o Eucalyptus saligna, verificaram decréscimo da massa específica básica até as posições correspondentes a $25-50 \%$ da altura comercial, com valores crescentes partindo desses pontos até o topo.

A variação da massa específica no sentido base-topo é maior para o Eucalyptus grandis do que para o Eucalyptus saligna, indicando que essa espécie é mais heterogênea nesse sentido (Souza et al., 1986). Segundo o mesmo autor, a correlação linear da média da árvore com cada posição estudada mostrou valores mais altos para o coeficiente de correlação nas posições $25-50 \%$ da altura comercial para todas as procedências de ambas as espécies, indicando que essas posições estimam melhor a massa específica média da árvore e não o DAP como muitos autores citam. Na base da árvore, há influência do sistema radicular na massa específica básica e no topo há influência da copa, ramificações, etc. Sendo assim, as posições que sofrem menor influência estão mais ou menos no intervalo compreendido entre $25-50 \%$ da altura comercial.

\section{Na casca}

O efeito tecnológico e econômico, em conseqüência do comportamento da casca nas espécies utilizadas para a produção de carvão vegetal, constitui um problema para os setores florestais ligados à siderurgia (Paula Neto et al., 1991). Da mesma forma, a casca normalmente deve ser eliminada na produção de celulose, chapas aglomeradas e de fibra. Para os referidos setores, é importante conhecer a percentagem de casca existente e o seu comportamento ao longo do tronco. Por outro lado, de acordo com Silva et al. (1983), a casca pode contribuir, em combinação com a madeira, com certa parcela da energia fornecida por um povoamento florestal. Para o autor, a casca seca da madeira de Eucalyptus viminalis produz 3.495 $\mathrm{kcal} / \mathrm{kg}$ (poder calorífico superior), comparado com $4691 \mathrm{kcal} / \mathrm{kg}$ para madeira seca da mesma espécie. Em geral, um valor de $4.500 \mathrm{kcal} / \mathrm{kg}(5,23 \mathrm{kw} \mathrm{hr} / \mathrm{kg})$ de madeira seca de eucalipto pode ser tomado como médio. A umidade da madeira diminui o poder calorífico da madeira consideravelmente, em função da maior energia necessária para aquecer e evaporar a água (Stamm, 1964).

Paula Neto et al. (1992), em estudos da variação da percentagem de casca ao longo do tronco para as espécies Eucalyptus grandis, saligna e alba, verificaram que as percentagens de casca observadas nas várias alturas do tronco das árvores, para cada classe de DAP, diferem estatisticamente entre si, sendo menores nas maiores alturas e tendendo a estabilizar acima de $4 \mathrm{~m}$ de altura. À medida que aumenta a altura, o acréscimo na percentagem de casca é mais pronunciado nas menores classes de DAP, sendo insignificante para as maiores classes.

\section{MATERIAL E MÉTODOS}

As amostras de madeira de Eucalyptus grandis W Hill ex-Maiden foram obtidas de um experimento, instalado com mudas produzidas com base em sementes, no município de Rio Pardo, estado do Rio Grande do Sul, na propriedade da Associação dos Fumicultores do Brasil (AFUBRA). O clima da região, de acordo com a classificação climática de Köppen é do tipo Cfa, com temperatura média do mês mais quente em torno de $25,1^{\circ} \mathrm{C}$, temperatura média do mês mais frio em torno de $14,1^{\circ} \mathrm{C}$, e a precipitação média anual é da ordem de 1699 mm (Moreno, 1961). De acordo com Lemos (1973), os solos da área pertencem à unidade de mapeamento Rio Pardo, os quais são profundos, de coloração avermelhada em toda a extensão do perfil, argilosos, bem drenados e derivados de siltitos finos da Formação Rio Pardo. Apresentam limitações pela fertilidade natural que é baixa, sendo fortemente ácidos, com saturação de bases baixa, relativamente pobres em nutrientes, com teores de alumínio trocável ponderável. O plantio foi realizado em 1992, e os tratamentos aplicados foram definidos pelo espaçamento inicial, num total de doze, conforme mostra a Tabela 1. As linhas de plantio foram orientadas no sentido norte-sul. 
A coleta das amostras foi realizada no ano de 2002, quando o povoamento estava com 10 anos de idade. Para cada tratamento, foram selecionadas três árvores de DAP médio ( $\bar{X} \pm 1$ desvio-padrão) as quais foram abatidas e após as medições das alturas total e comercial, procedeu-se à retirada de discos de aproximadamente 2,5 cm de espessura, correspondentes à base, DAP, 25, 50, 75 e 100\% da altura comercial, que foram acondicionados em sacos de polietileno e enviados ao Laboratório de Produtos Florestais da UFSM.

Em cada disco, foram determinados os diâmetros com e sem casca, e em seguida, retiradas cunhas diametralmente opostas as quais foram submersas em água até atingirem a saturação (peso constante). A seguir foi determinada a ME seguindo a metodologia sugerida pela ASTM D 2395-93 (1995).

TABELA 1: Tratamentos utilizados no experimento.

TABLE 1: Treatments used in the experiment.

\begin{tabular}{c|c|c}
\hline Tratamento & $\begin{array}{c}\text { Espaçamento }(\mathrm{m}) \\
\text { (entre linha } \times \text { entre árvore) }\end{array}$ & $\begin{array}{c}\text { Área vital } \\
\left(\mathrm{m}^{2}\right)\end{array}$ \\
\hline 1 & $1 \times 1$ & 1,00 \\
2 & $1 \times 1,5$ & 1,50 \\
3 & $2 \times 1$ & 2,00 \\
4 & $2 \times 1,5$ & 3,00 \\
5 & $2 \times 2$ & 4,00 \\
6 & $2 \times 2,5$ & 5,00 \\
7 & $2,5 \times 1,5$ & 3,75 \\
8 & $2,5 \times 2,5$ & 6,25 \\
9 & $3 \times 2$ & 6,00 \\
10 & $3 \times 2,5$ & 7,50 \\
11 & $3 \times 3$ & 9,00 \\
12 & $3 \times 4$ & 12,00 \\
\hline
\end{tabular}

Após a obtenção da ME em cada posição relativa do tronco, foi determinada a ME média da árvore, pela ponderação dos valores de ME obtida em cada posição com os volumes correspondentes entre duas posições sucessivas, de acordo com a metodologia sugerida por Vital (1984).

As etapas realizadas para a determinação da ME da madeira também foram observadas para a casca. Para a obtenção do volume total com e sem casca, foram utilizadas funções de produção estabelecidas por Schneider et al. (2002), para o mesmo povoamento e para cada tratamento. Em seguida, foi determinada a massa seca de madeira (MS) e de casca (MS casca), multiplicando-se a ME pelo volume estimado para cada tratamento.

Os resultados foram analisados pela análise de regressão, sendo os modelos selecionados com base na significância do modelo e dos coeficientes na equação de regressão, na distribuição dos resíduos, nos maiores valores de $\mathrm{F}$ e coeficiente de determinação e no menor valor do erro-padrão da estimativa.

\section{RESULTADOS E DISCUSSÃO}

\section{Massa específica básica em função da altura comercial}

Conforme a Figura 1, verifica-se que a ME da madeira decresce da base para o DAP, aumentando levemente até $75 \%$, seguindo então tendência decrescente até os $100 \%$ da altura comercial. Os maiores valores de ME foram encontrados na base e $75 \%$ da altura da árvore o que coincide com as observações de Souza et al. (1986) para Eucalyptus grandis e Eucalyptus saligna. 


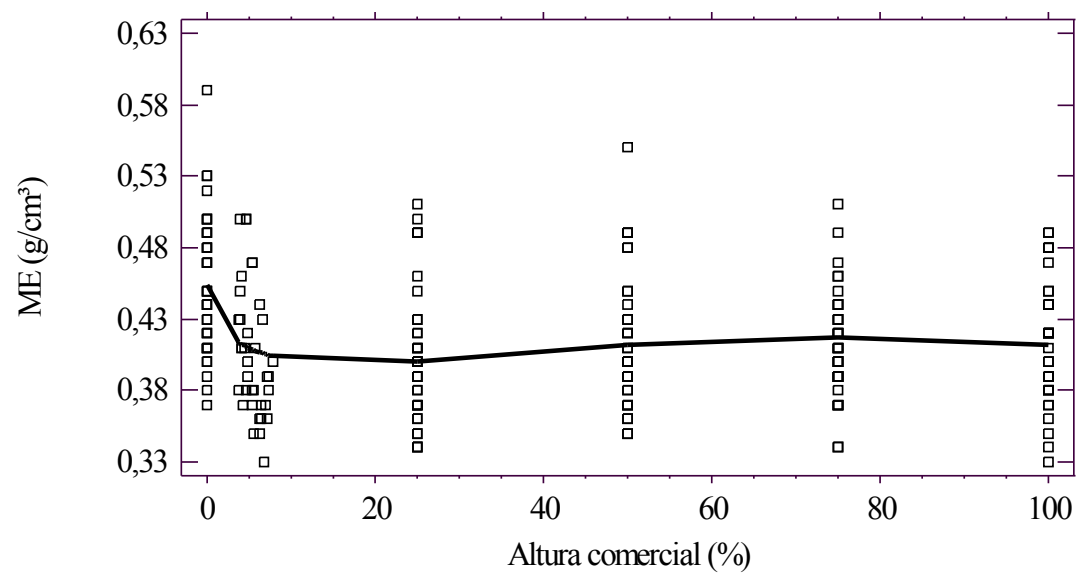

FIGURA 1: Massa específica básica da madeira em função da altura comercial.

FIGURE 1: Basic density of the wood as a function of commercial height.

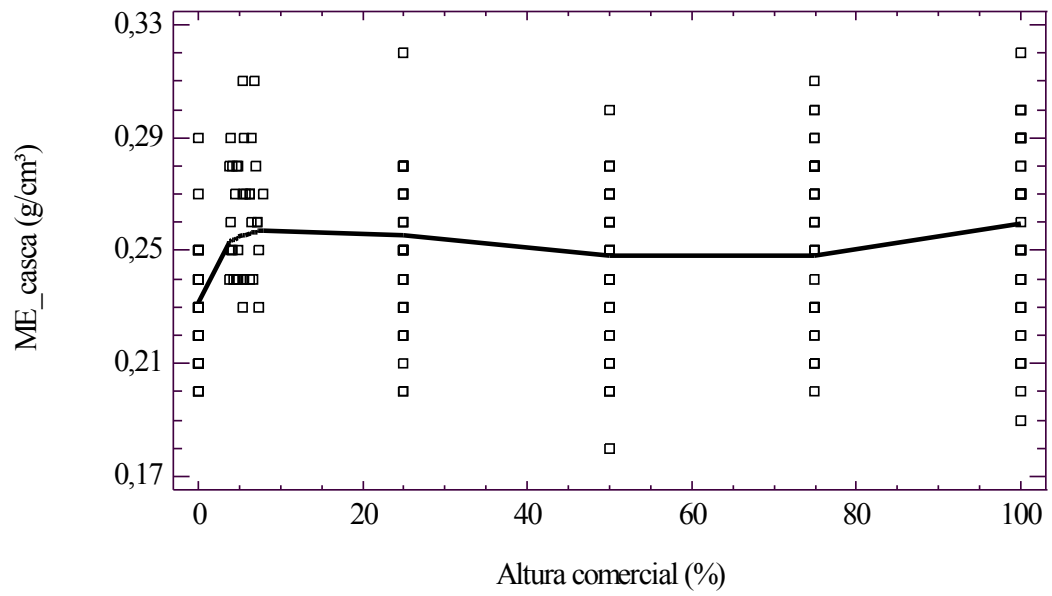

FIGURA 2: Massa específica básica da casca em função da altura comercial.

FIGURE 2: Basic density of the bark as a function of commercial height.

Já para a ME da casca, observa-se tendência oposta ao da ME ao longo do tronco. A Figura 2 mostra que a ME da casca aumenta da base para o DAP, decresce até os 50\%, voltando a aumentar acima desse ponto até os $100 \%$ da altura comercial. Os maiores valores de ME da casca foram encontrados no DAP e a $100 \%$ da altura comercial. As equações de regressão ajustadas para ME e ME da casca em função da posição axial são apresentadas na Tabela 2.

TABELA 2: Equações ajustadas para estimar a massa específica básica da madeira e da casca em função da posição axial em relação à altura comercial.

TABLE 2: Adjusted equations to estimate wood and bark basic density as a function of stern position in relations ship to the commercial height.

\begin{tabular}{lccc}
\hline Equação & $\mathrm{S}_{\mathrm{yx}}$ & $\mathrm{R}_{\mathrm{aj}}^{2}$ & $\mathrm{~F}$ \\
\hline$M E=0,454196-0,028566 \sqrt{\mathrm{p}}+0,003937 p-0,000015 p^{2}$ & 0,0445 & 12,10 & $10,86^{*}$ \\
$M E_{C}=0,231651+0,01592 \sqrt{\mathrm{p}}-0,002527 p-0,000012 p^{2}$ & 0,0285 & 8,10 & $7,32^{*}$ \\
\hline
\end{tabular}

Em que: $*$ = Significativo a $1 \%$ de probabilidade; $\mathrm{ME}=$ massa específica básica da madeira $\left(\mathrm{g} / \mathrm{cm}^{3}\right) ; \mathrm{ME}_{\mathrm{c}}=$ massa específica básica da casca $\left(\mathrm{g} / \mathrm{cm}^{3}\right) ; \mathrm{p}=$ posição axial $(\%) ;$ Syx $=$ erro-padrão da estimativa; $\mathrm{R}_{\mathrm{aj}}^{2}=$ coeficiente de determinação; $\mathrm{F}=\mathrm{F}$ calculado. 


\section{Massa específica básica em função dos tratamentos}

Os resultados de ME e MS em função dos tratamentos são mostrados na Tabela 3. A ME média foi de $0,411 \mathrm{~g} / \mathrm{cm}^{3}$ para a madeira (coeficiente de variação $(\mathrm{CV})$ de $9,72 \%$ ) e $0,250 \mathrm{~g} / \mathrm{cm}^{3}$ para a casca $(\mathrm{CV}=$ 7,90\%). A MS média estimada da madeira foi de 191,19 ton/ha $(\mathrm{CV}=25,67 \%)$ e de 18,74 ton/ha $(\mathrm{CV}=$ $19,85 \%)$ de casca.

Pode-se observar que os tratamentos, que apresentaram maiores valores de MS, foram o $2\left(1,5 \mathrm{~m}^{2}\right)$ e o $4\left(3 \mathrm{~m}^{2}\right)$. Esses foram os tratamentos que apresentaram também os maiores valores de ME e ME_casca.

TABELA 3: Massa específica básica e massa seca da madeira e da casca em função dos espaçamentos entre linhas e entre árvores.

TABLE 3: Wood and bark basic densities and dry mass as a function of between lines and tree spacing.

\begin{tabular}{c|c|c|c|c|c|c|c}
\hline Tratamento & $\begin{array}{c}\text { Entre } \\
\text { Linhas } \\
(\mathrm{m})\end{array}$ & $\begin{array}{c}\text { Entre Árvores } \\
(\mathrm{m})\end{array}$ & $\begin{array}{c}\text { Espaço Vital } \\
\left(\mathrm{m}^{2}\right)\end{array}$ & $\begin{array}{c}\mathrm{ME} \\
\left(\mathrm{g} / \mathrm{cm}^{3}\right)\end{array}$ & $\begin{array}{c}\mathrm{ME}_{\text {casca }} \\
\left(\mathrm{g} / \mathrm{cm}^{3}\right)\end{array}$ & $\begin{array}{c}\mathrm{MS} \\
(\text { ton/ha })\end{array}$ & $\begin{array}{c}\mathrm{MS}_{\text {casca }} \\
(\text { ton/ha) }\end{array}$ \\
\hline 1 & 1,0 & 1,0 & 1,00 & 0,40 & 0,26 & 210 & 20 \\
2 & 1,5 & 1,0 & 1,50 & 0,44 & 0,28 & 272 & 23 \\
3 & 2,0 & 1,0 & 2,00 & 0,41 & 0,26 & 214 & 20 \\
4 & 2,0 & 1,5 & 3,00 & 0,47 & 0,27 & 257 & 22 \\
5 & 2,5 & 1,5 & 3,75 & 0,39 & 0,24 & 176 & 18 \\
6 & 2,0 & 2,0 & 4,00 & 0,41 & 0,24 & 201 & 19 \\
7 & 2,5 & 2,0 & 5,00 & 0,38 & 0,24 & 158 & 18 \\
8 & 2,5 & 2,5 & 6,25 & 0,45 & 0,27 & 215 & 21 \\
9 & 3,0 & 2,0 & 6,00 & 0,40 & 0,25 & 168 & 18 \\
10 & 3,0 & 2,5 & 7,50 & 0,42 & 0,24 & 160 & 17 \\
11 & 3,0 & 3,0 & 9,00 & 0,40 & 0,24 & 172 & 18 \\
12 & 4,0 & 3,0 & 12,00 & 0,38 & 0,23 & 91 & 9 \\
\hline
\end{tabular}

Em que: Cada valor é uma média de três árvores. $\mathrm{ME}=$ massa específica básica da madeira; $\mathrm{ME}_{\text {casca }}=$ massa específica básica da casca; $\mathrm{MS}=$ massa seca de madeira; $\mathrm{MS}_{\text {casca }}=$ massa seca de casca.

A Tabela 4 mostra o modelo selecionado, juntamente com os seus coeficientes e as estatísticas obtidas para a tendência da variação da ME em função do espaço vital.

TABELA 4: Equações ajustadas para estimar a massa específica básica e a massa seca de madeira em função do espaçamento entre linhas e entre árvores.

TABLE 4: Adjusted equations to estimate the basic density and the dry mass of wood as a function of between lines and tree spacing.

\begin{tabular}{|c|c|c|c|c|}
\hline Equação & $\mathrm{R}_{\text {aj }}^{2}$ & $\mathrm{~F}$ & $\mathrm{~S}_{\mathrm{yx}}$ & $\begin{array}{l}\text { Valor de } \mathrm{p} \\
\quad(\%)\end{array}$ \\
\hline$\frac{1}{\sqrt{M E}}=1,34866+0,07938 L+\frac{0,15080}{\mathrm{~A}^{2}}$ & 14,86 & 4,06 & 0,0339 & 2,66 \\
\hline$\frac{1}{\sqrt{M E_{C}}}=1,73505+0,10112 L+\frac{0,12489}{\mathrm{~A}^{2}}$ & 17,82 & 4,79 & 0,0289 & 1,49 \\
\hline$\frac{1}{M S}=-0,00400+0,00359 L+\frac{0,00530}{\mathrm{AL}}$ & 85,62 & 105,22 & 0,0007 & $<0,00$ \\
\hline$\frac{1}{M S_{C}}=-0,04380+0,03702 L+\frac{0,06033}{\mathrm{~A} \mathrm{~L}}$ & 80,42 & 72,90 & 0,0026 & $<0,00$ \\
\hline
\end{tabular}

Em que: $\mathrm{ME}=$ massa específica básica da madeira $\left(\mathrm{g} / \mathrm{cm}^{3}\right) ; \mathrm{L}=$ espaçamento entre linhas $(\mathrm{m}) ; \mathrm{A}=$ espaço vital $(\mathrm{E} \times \mathrm{L})$; $\mathrm{E}=$ espaçamento entre árvores $(\mathrm{m}) ; \mathrm{ME}_{\mathrm{C}}=$ Massa específica básica da casca $\left(\mathrm{g} / \mathrm{cm}^{3}\right) ; \mathrm{MS}=$ massa seca de madeira (ton/ha); $\mathrm{MS}_{\mathrm{c}}=$ massa seca de casca (ton/ha); $\mathrm{R}_{\mathrm{aj}}{ }_{\mathrm{j}}=$ coeficiente de determinação; $\mathrm{F}=\mathrm{F}$ calculado; $\mathrm{S}_{\mathrm{yx}}=$ erro-padrão da estimativa; valor de $\mathrm{p}=$ significância do modelo (\%).

Pode-se notar que o efeito do espaçamento na ME, apesar de significativo pelo modelo ajustado, é pequeno (aproximadamente $15 \%$ da variação na ME pode ser explicada pela variação no espaço vital). Para 
Berger (2000), trabalhando com clones de Eucalyptus saligna, ocorre um aumento da ME com o aumento do espaçamento o que não pode ser comprovado no presente trabalho para os maiores espaçamentos. Garcia et al. (1991) encontraram uma diminuição da ME da madeira com o aumento do espaçamento. Já Vital e Della Lucia (1987) observaram não haver efeito significativo do espaçamento na ME da madeira e da casca. Essas divergências de resultados podem ser decorrentes de diversos fatores, entre eles a variabilidade genética dos povoamentos originados de sementes, conforme sugerem Ferreira (1968) e Mello et al. (1976). A ME da casca seguiu a mesma tendência da variação da ME da madeira.

\section{Massa seca de madeira e de casca em função dos tratamentos}

A quantidade de massa seca de madeira por hectare foi influenciada pelo espaçamento, conforme pode ser observado na Tabela 4. A massa seca de madeira diminuiu com o aumento do espaço vital $\left(\mathrm{m}^{2}\right)$, sendo o tratamento com 1,5 $\mathrm{m}^{2}$ o que apresentou maior valor de massa seca de madeira (ton/ha), seguido pelo tratamento com $3,0 \mathrm{~m}^{2}$.

Os resultados obtidos não coincidem com os encontrados por Berger (2000) ao afirmar que a massa seca de madeira não sofreu influência do espaço vital, e Mello et al. (1971) que encontraram maior rendimento de massa seca de madeira com o aumento do espaço vital.

De acordo com os resultados, a maior produção de massa seca de madeira por unidade de área está relacionada com o número de árvores por hectare e também com a ME da madeira A determinação da massa seca é obtida pela multiplicação do volume de sólido pela ME, e como o volume total por hectare aumenta com o número de árvores (Schneider, 1993), isso ocasiona um aumento na massa seca nos espaçamentos menores. Os resultados são similares aos encontrados por Souza (1989) que relatou uma maior produção em peso e volume no menor espaçamento estudado, porém tendendo a se igualar acima de 114 meses.

A variação verificada para a massa seca de madeira em função do espaço vital, também pode ser observada para a massa seca em função do espaçamento entre linhas, onde os maiores valores encontrados foram para os menores tratamentos. O espaçamento entre árvores causou menor influência do que o espaçamento entre linhas. Possivelmente, isso seja por causa da luminosidade, já que as linhas eram orientadas no sentido norte-sul.

A massa seca de casca em função do espaço vital e espaçamento entre linhas, pode ser estimada com base nas equações apresentadas na Tabela 4. Observa-se, para a massa seca de casca, as mesmas tendências encontradas para a massa seca de madeira, tanto em função do espaço vital como do espaçamento entre linhas.

Sugerem-se maiores estudos para verificar o efeito dessas variáveis, que são associadas ao espaço vital e à luminosidade, sobre a produção em massa seca. Da mesma forma, o estabelecimento de experimentos clonais que tenderiam a limitar a variabilidade a fatores ambientais.

Uma dificuldade encontrada para determinar com maior precisão o efeito da distância entre linhas e entre árvores nos parâmetros estudados foi a descontinuidade dos tratamentos. Dessa forma, as equações ajustadas só devem ser extrapoladas com cuidado, pois podem não refletir a realidade.

\section{CONCLUSÕES}

Os resultados obtidos no presente trabalho permitiram as seguintes conclusões:

A ME da madeira foi influenciada pelas diferentes posições axiais da árvore, sendo que os maiores valores de ME foram encontrados na base e a 75\% da altura comercial da árvore.

Verificou-se que a quantidade de massa seca de madeira por hectare diminui com o aumento do espaço vital. A variação da massa seca de casca, em função do espaço vital, seguiu a mesma tendência da massa seca de madeira.

Como os maiores valores de massa seca, tanto para madeira como para casca, foram observados nos menores espaçamentos (1,5x1 e 2x1,5 m), estes são recomendados para o plantio de florestas de Eucalyptus grandis com a finalidade de uso energético. Porém, deve-se levar em conta o custo de implantação, condução e colheita da floresta para que se possa obter um equilíbrio entre produção e custo.

Ciência Florestal, v. 13, n. 2, 2003 


\section{REFERÊNCIAS BIBLIOGRÁFICAS}

ASTM. American Society for Testing and Materials. Test methods for specific gravity of wood and wood-base materials, D 2395-93. Philadelphia, 1995b.

BALLONI, E.A.; SIMÕES, J.W. O espaçamento de plantio e suas implicações silviculturais. IPEF, p. 1-16, 1980. (Série Técnica, 3).

BAMPI, P. Manejo de Pinus na empresa Papel e Celulose Catarinense - PCC. In: SIMPÓSIO MANEJO DE FLORESTAS PLANTADAS, 1991, Esteio. Anais... Santa Maria: UFSM/CEPEF,1991. p.48-66.

BRASIL, M.A.M.; FERREIRA, M. Variação da densidade básica da madeira de Eucalyptus alba Reinw, Eucalyptus saligna Smith e Eucalyptus grandis aos 5 anos de idade em função do local e do espaçamento. IPEF, v.2, n.3, p.129149, 1971.

BERGER, R. Crescimento e qualidade da madeira de um clone de Eucalyptus saligna Smith sob o efeito do espaçamento e da fertilidade. 2000. 106p. Dissertação (Mestrado em Ciências Florestais) - Universidade Federal de Santa Maria, Santa Maria, 2000.

BUSNARDO, C.A. et al. Em busca da qualidade ideal da madeira do eucalipto para produção de celulose. IV. Altura ideal de amostragem para avaliação da densidade média para árvores de Eucalyptus grandis. In: CONGRESSO ANUAL DA ABCP, 1987, São Paulo. Anais... São Paulo: Associação Brasileira de Celulose e Papel, 1987.

CARVALHO, A.M.; CAMARGO, F.R.A. Variação da densidade básica entre procedências e progênies de Eucalyptus saligna. O Papel, São Paulo, n.6, p.56-59, 1996.

FERREIRA, M. Estudo da variação da densidade básica da madeira de Eucalyptus alba Reiw e Eucalyptus salignia Smith. 1968. 71 p. Tese (Doutourado) - Escola Superior de Agricultura "Luiz de Queiroz", Piracicaba, 1968.

FERREIRA, M. Estudos da variação da densidade básica da madeira de Eucalyptus alba Reinw e Eucalyptus saligna Smith. IPEF, Piracicaba, n. 2-3, p.83-96, 1970.

FERREIRA, M.; KAGEYAMA, P.Y. Melhoramento genético da densidade da madeira de eucalipto. Boletim Técnico IPEF, v. 6, n. 20, p. A1-A15, 1978.

FOELKEL, C.E.B.; BARRICHELO, L.E.G.; MILANEZ, A.F. Estudo comparativo das madeiras de Eucalyptus saligna, Eucalyptus paniculata, Eucalyptus citriodora, Eucalyptus maculata e Eucalyptus tereticorns parar a produção de celulose sulfato. IPEF, Piracicaba, v.10, p.17-37, 1975.

GARCIA, C.H.; CORRADINE, L.; ALVARENGA, S.F. Comportamento florestal do Eucalyptus grandis e Eucalyptus saligna em diferentes espaçamentos. IPEF, p. 1-8, 1991. (Circular Técnica, 179).

LEMOS, R. C.; AZOLIN, M. D.; ABRÃ̃O, P. V. R.; SANTOS, M. C. L. Levantamento e reconhecimento dos solos do estado do Rio Grande do Sul. Recife: Ministério da Agricultura. Departamento Nacional de Pesquisas Agropecuárias - Divisão de Pesquisas Pedológicas, 1973. 431p. (Boletim Técnico, 30)

MELLO, H.A.; MASCARENHAS SOBRINHO, J.; SIMÕES, J.W.; DO COUTO, H.T.Z. Influência do espaçamento e da idade de corte na produção de madeira de eucalipto em solo de cerrado. IPEF, v. 13, p.143-162, 1976.

. Influência do espaçamento na produção de madeira de eucalipto em solo de cerrado. IPEF, v. 2-3, p.3-30, 1971.

MORENO, J. A. Clima do Rio Grande do Sul. Porto Alegre: Secretaria da Agricultura, 1961. 42p.

PAULA NETO, F.; LEITE, H.G.; NUNES, J.R.S.; CAMPOS, J.C.C. Análise do volume de casca de reflorestamento de Eucalyptus de diferentes idades e condições de local, espécies e método de regeneração. Revista Árvore, v. 15, n. 1, p. 55-65, 1991.

PAULA NETO, F., LEITE, H.G., NUNES, J.R.S., CAMPOS, J.C.C. Variação da percentagem de casca ao longo do tronco e entre árvores de eucalipto. Revista Árvore, v. 16, n. 3, p. 309-318, 1992.

RIBEIRO, F.A.; ZANI, J. Variação da densidade básica da madeira em espécies/procedências de Eucalyptus spp. IPEF, n. 46, p. 76-85, 1993.

SCHNEIDER, P.R. Introdução ao manejo florestal. Santa Maria: UFSM/CEPEF - FATEC, 1993. 348p.

SCHNEIDER, P.R.; HOPPE, J.; FARIAS, J.; FREDDO, A.R. Influência do espaçamento de plantio na produtividade de Eucalyptus grandis no município de Rio Pardo, RS. Santa Maria: UFSM, 2002. 16p. Relatório de Pesquisa do Convênio CEPEF/AFUBRA.

SMITH, D.M. The practice of silviculture. New York: John Wiley e Sons, 1962, 578p.

SOUZA, R.N. Efeito de dois espaçamentos na produção em peso e volume de Eucalyptus grandis (W. Hill ex 
Maden). 1989. 102p. Dissertação (Mestrado em Ciências Florestais) - Universidade Federal de Viçosa, Viçosa, 1989.

SOUZA, V.R.; CARPIM, M.A.; BARRICHELO, L.E.G. Densidade básica entre procedências, classes de diâmetro e posição em árvores de Eucalyptus grandis e Eucalyptus saligna. IPEF, Piracicaba, v. 3, p. 63-72, 1986.

SILVA, L.B.X.; NETO, F.R.; TOMASELLI, I.. Estudo comparativo da produção de biomassa para energia entre 23 espécies florestais. In: CONGRESSO FLORESTAL BRASILEIRO, 4., 1982, Belo Horizonte. Anais... Belo Horizonte: SBS/IBDF/CNPQ/FINEP, 1983. p 872-878.

STAMM, A.J. Wood and celullose science. New York: The Ronald Press Company, 1964. 549p.

TOMAZELLO FILHO, M. Variação radial da densidade básica e da estrutura anatômica da madeira do Eucalyptus saligna e Eucalyptus grandis. IPEF, n. 29, p. 37-45, 1985.

VITAL, B.R.; DELLA LUCIA, R.M. Efeito do espaçamento na produção em peso e na qualidade da madeira de Eucalyptus grandis e Eucalyptus saligna aos 52 meses de idade. Revista Árvore, v. 11, n. 2, p.132-145, 1987.

VITAL, B.R. Métodos de determinação da densidade da madeira. SIF/UFV Boletim Técnico, n. 1, p. 1-21, 1984. 